\title{
Poly(benzyl ether) dendrons without conventional gelation motifs as a new kind of effective organogelators
}

\author{
FENG Yu, LIU ZhiXiong, WANG LiYing, CHEN Hui, HE YanMei* \& FAN QingHua* \\ Beijing National Laboratory for Molecular Sciences, CAS Key Laboratory of Molecular Recognition and Function, Institute of Chemistry, \\ Chinese Academy of Sciences, Beijing 100190, China
}

Received May 2, 2012; accepted June 12, 2012; published online September 14, 2012

\begin{abstract}
Two poly(benzyl ether) dendrons, decorated in their periphery with nitrile groups, were divergently synthesized and fully characterized. Their gelation properties were studied by using scanning electron microscopy (SEM), X-ray crystal structure analysis and concentration- and temperature-dependent ${ }^{1} \mathrm{H}$ NMR spectroscopy. It was found that the gelation capability of these dendrons was highly dependent on dendron generation, and the second-generation dendron $\mathrm{G}_{2}-\mathrm{CN}$ proved to be highly efficient organogelator despite the lacking of any conventional gelation motifs, such as amides, long alkyl side chains and steroidal groups. The multiple strong $\pi-\pi$ stacking interactions and hydrogen bonding interactions due to the peripheral isophthalonitrile motifs were proved to be the main driving forces to form the self-assembled gel.
\end{abstract}

dendron, organogelator, self-assembly

Citation: Feng Y, Liu Z X, Wang L Y, et al. Poly(benzyl ether) dendrons without conventional gelation motifs as a new kind of effective organogelators. Chin Sci Bull, 2012, 57: 4289-4295, doi: 10.1007/s11434-012-5479-2

Over the past decades, dendritic gelators have gained much interest due to the advantages of significant steric impact and capability of forming multiple noncovalent interactions [1-3]. So far, a great number of physically thermo-reversible hydrogel and organogel systems based on dendrimers or dendrons with different chemical structures and functionalities have been reported [4-23]. In 1986, Newkome and coworkers [4,5] initiated the field of dendritic supramolecular gels by reporting a series of arborol-shaped hydrogelators. Aida and co-workers [7] have reported the first example of dendritic organogel in 2000 by using an ester-terminated Fréchet-type dendrons with a dipeptide focal core. Since then, great attention has been focused on the design of novel dendritic gelators with highly gelation properties. For example, Smith and co-workers [10,11] have systematically studied both one-component and two-component dendritic gelators based on lysine. Jia and co-workers [12-14] have reported a series of dendritic organogel with lyotropic liquid

*Corresponding authors (email: fanqh@iccas.ac.cn; heym@iccas.ac.cn) crystals properties based on glycine and $L$-aspartic acid. Lately, Liu and co-workers [19] have synthesized a series of $L$-glutamate based aromatic dendrons as ambidextrous gelators of water and organic solvents. Among these successful examples reported, the incorporation of amide units into the core or the branches of the dendritic organogelators has been considered very necessary for the effective gelation process. However, it remains a great challenge to date in the design of effective dendritic organogelators with no conventional gelation motifs such as peptide and long alkyl chains [22,23].

We previously reported a series of peripherally dimethyl isophthalate-functionalized poly(benzyl ether) dendrons, which could act as a highly efficient dendritic organogelator despite the lacking of any conventional gelating motifs [24,25]. The multiple strong $\pi-\pi$ stacking interactions due to the peripheral dimethyl isophthalate motifs and non-typical hydrogen bonding were found to be the key contributor in forming the self-assembled gel. Encouraged by these exciting results, we wish to extend such dendritic gelator system 
with cyano group as substituent instead of methyl ester. This choice was based on the following facts: (a) cyano is more stable than methyl ester to hydrolysis; (b) cyano substituent is an electron-withdrawing group and capable of forming coplanar with aromatic ring, which is favorable for forming the strong $\pi-\pi$ stacking with other electron-rich aromatic ring; (c) incorporation of nitrile group into the periphery of dendron will also provide other non-covalent interactions, such as hydrogen-bonding and van der Waals interactions [26-28]. Therefore, it is expected that incorporation of nitrile group into the periphery of dendron would lead to a new kind of efficient and more stable dendritic organogelators. To test our hypothesis, in this work, we synthesized two peripherally isophthalonitrile (IPN)-functionalized poly(benzyl ether) dendrons. Their gelation behavior, aggregation microstructures and driving forces of the gel-phase assemblies were investigated.

\section{Experimental}

\subsection{General information}

All starting materials were obtained from commercial suppliers and used as received. All solvents were distilled with suitable drying agents. Moisture-sensitive reactions were performed under an atmosphere of dry argon. ${ }^{1} \mathrm{H}$ NMR and ${ }^{13} \mathrm{C}$ NMR spectra were recorded on Bruker AMX 300 Spectrometer $\left({ }^{1} \mathrm{H}: 300 \mathrm{MHz} ;{ }^{13} \mathrm{C}: 75 \mathrm{MHz}\right)$ or Bruker AMX-600 spectrometers $\left({ }^{1} \mathrm{H}: 600 \mathrm{MHz} ;{ }^{13} \mathrm{C}: 150 \mathrm{MHz}\right)$ at $298 \mathrm{~K}$. Chemical shifts were reported in parts per million relative to the internal standards, partially deuterated solvents or tetramethylsilane (TMS). HR-ESI mass spectra were obtained on a Bruker APEX IV instrument. Elemental analyses were performed on a Carlo-Erba-1106 instrument. Field emission scanning electron microscopy (FE-SEM) was performed by using a Hitachi S-4800 system with an accelerating voltage of $15 \mathrm{kV}$. Samples for FE-SEM were prepared by spinning the gels on silicon slices and dried by air for $2 \mathrm{~d}$. To minimize sample charging, a thin layer of $\mathrm{Au}$ was deposited onto the samples before SEM examination.

\subsection{X-ray single crystal structure analysis of $\mathbf{G}_{1}-\mathrm{CN}$}

A single crystal suitable for X-ray diffraction was obtained by slow evaporation of acetonitrile/methanol $(4: 1, \mathrm{v} / \mathrm{v})$ solution at room temperature. All data were collected on a Rigaku Saturn X-ray diffractometer with graphite-monochromator Mo K $\alpha$ radiation $(\lambda=0.71073 \AA)$ at $113 \mathrm{~K}$. Intensities were collected for absorption effects using the multiscan technique SADABS. The structures were solved by direction methods and refined by a full matrix least squares technique based on $F^{2}$ using SHELXL 97 program (Sheldrick, 1997). The extended packing plots and data from crystal packing were obtained using the software Mercury 1.4.1.

\subsection{Gelation test for organic fluids}

A solution containing a certain weighed amount of gelator $\mathrm{G}_{m}-\mathrm{CN}(m=1,2)$ in an organic solvent was heated in a sealed $1 \mathrm{~cm}$-diameter test tube in an oil bath until the solid was dissolved. If the compound was unable to dissolve, it was noted as insoluble (I). After the solution was allowed to stand at room temperature overnight, the state of the mixture was evaluated by the "stable to inversion of a test tube" method. If no flow was observed when inverting the vial, a stable gel was formed and noted as gelation (G). If part of the mixture formed a gel but flow was still observed, the phenomenon was recorded as partial gelation (PG). If precipitation occurred, $\mathrm{P}$ was noted, and if the clear solution ( $>60 \mathrm{mg} / \mathrm{mL}$ ) was retained, it was marked as soluble (S). In some solvents, short-term sonication $\left(0.40 \mathrm{~W} / \mathrm{cm}^{2}, 40 \mathrm{kHz}\right.$, 1-3 min) was needed at the beginning of the cooling process. The reversibility of the gelation was confirmed by repeated heating and cooling cycles. The critical gelator concentrations (CGCs) were determined from the minimum amount of gelator required for the formation of gel at room temperature.

The thermally reversible gel-sol transition temperature $\left(T_{\text {gel }}\right)$ was determined by using a tube-inversion methodology [29]. A sealed vial containing the gel was immersed upside-down in a thermostated water bath. The temperature of the bath was raised at a rate of approximately $2^{\circ} \mathrm{C} / \mathrm{min}$. $T_{\text {gel }}$ was defined as the temperature at which the gel moved on tilting of the vial. The experimental error of $T_{\text {gel }}$ in repeated independent measurements was less than $1^{\circ} \mathrm{C}$.

\subsection{Synthesis and characterizations}

The dendrons $\mathrm{G}_{n}-\mathrm{CH}_{2} \mathrm{OH}(n=0,1)$ were synthesized according to previously reported synthetic procedures $[24,30]$. The synthesis route of $\mathrm{G}_{m}-\mathrm{CN}(m=1,2)$ is shown in Scheme 1 .

$\mathrm{G}_{2}-\mathrm{CN}$ : To an ice-bath cooled solution of $\mathrm{G}_{1}-\mathrm{CH}_{2} \mathrm{OH}$ (1.066 g, $2.063 \mathrm{mmol})$, 5-hydroxyisophthalonitrile (1.338 g, $9.286 \mathrm{mmol})$, triphenylphosphine $\left(\mathrm{PPh}_{3}, 2.436 \mathrm{~g}, 9.286\right.$ $\mathrm{mmol})$ in dry THF $(30 \mathrm{~mL})$ was added diisopropylazodicarboxylate (DIAD, $1.878 \mathrm{~g}, 9.286 \mathrm{mmol}, 1.86 \mathrm{~mL}$ ) dropwise via syringe. The reaction mixture was stirred for 10 min at $0^{\circ} \mathrm{C}$ and then $48 \mathrm{~h}$ at $50^{\circ} \mathrm{C}$ under a nitrogen atmosphere. The reaction was monitored by TLC upon the completion. The crude product was purified as follows: The reaction mixture (about $30 \mathrm{~mL}$ ) was added to methanol (200 $\mathrm{mL}$ ) under vigorous stirring, and the precipitate was isolated by filtration; then, the resulting precipitate was purified by flash column chromatography (silica gel, dichloromethaneethyl acetate, $30: 1$, v/v) to afford $\mathrm{G}_{2}-\mathrm{CN}$ as a white powder (1.791 g, 85\%). ${ }^{1} \mathrm{H}$ NMR (300 MHz, $\mathrm{CDCl}_{3}, \delta$ ): 5.07 (s, $\left.\mathrm{ArCH}_{2} \mathrm{O}, 4 \mathrm{H}\right), 5.08$ (s, $\left.\mathrm{ArCH}_{2} \mathrm{O}, 2 \mathrm{H}\right), 5.13$ (s, $\left.\mathrm{ArCH}_{2} \mathrm{O}, 8 \mathrm{H}\right)$, 7.00 (s, ArH, 4H), 7.02 (s, ArH, 4H), 7.08 (s, $\operatorname{ArH}, 1 \mathrm{H})$, 7.29-7.44 (m, $\mathrm{Ph} H+\mathrm{ArH}, 13 \mathrm{H}), 7.53$ (s, ArH, 4H). ${ }^{13} \mathrm{C}$ NMR $\left(75 \mathrm{MHz}, \mathrm{CDCl}_{3}, \delta\right): 159.6,159.5,158.8,138.4$, 
$137.3,128.7,128.2,127.8,127.6,122.6,118.5,118.2$, $116.5,115.1,113.8,113.6,70.4,70.2,70.0$. HRMS-ESI $(\mathrm{m} / \mathrm{z}):[\mathrm{M}+\mathrm{H}]^{+}$calcd. for $\mathrm{C}_{63} \mathrm{H}_{41} \mathrm{~N}_{8} \mathrm{O}_{7}, 1021.30927$; found, 1021.30721, [M+Na] ${ }^{+}$calcd. for $\mathrm{C}_{63} \mathrm{H}_{40} \mathrm{~N}_{8} \mathrm{NaO}_{7}, 1043.29122$; found, 1043.28851. Anal. calcd. for $\mathrm{C}_{63} \mathrm{H}_{40} \mathrm{~N}_{8} \mathrm{O}_{7}$ : C, 74.11; H, 3.95; N, 10.97; found: C, 73.69; H, 4.16; N, 10.54 .

$\mathrm{G}_{1}-\mathrm{CN}$ : Following the procedure for $\mathrm{G}_{2}-\mathrm{CN} . \mathrm{G}_{0}-\mathrm{CH}_{2} \mathrm{OH}$ (0.561 g, $2.296 \mathrm{mmol})$, 5-hydroxyisophthalonitrile $(0.827 \mathrm{~g}$, $5.741 \mathrm{mmol})$, triphenylphosphine $\left(\mathrm{PPh}_{3}, 1.506 \mathrm{~g}, 5.741\right.$ $\mathrm{mmol}$ ), diisopropylazodicarboxylate (DIAD, $1.161 \mathrm{~g}, 5.741$ mmol, $1.15 \mathrm{~mL})$ and anhydrous THF $(15 \mathrm{~mL})$ yielded $\mathrm{G}_{1}-\mathrm{CN}$ as a white powder $(0.798 \mathrm{~g}, 70 \%)$ after purification by precipitation and flash column chromatography. ${ }^{1} \mathrm{H}$ NMR (300 MHz, $\left.\mathrm{CDCl}_{3}, \delta\right): 5.18\left(\mathrm{~s}, \mathrm{ArCH}_{2} \mathrm{O}, 2 \mathrm{H}\right), 5.34$ (s, $\left.\mathrm{ArCH}_{2} \mathrm{O}, 4 \mathrm{H}\right), 7.19$ (s, ArH, 2H), 7.25 (s, $\left.\mathrm{ArH}, 1 \mathrm{H}\right)$, 7.30-7.49 (m, PhH, 5H), 7.77 (s, ArH, 4H), 7.84 (s, ArH, $2 \mathrm{H}) .{ }^{13} \mathrm{C} \mathrm{NMR}\left(75 \mathrm{MHz}, \mathrm{CDCl}_{3}, \delta\right): 160.3,160.1,138.8$, 138.0, 129.3, 128.8, 128.7, 128.5, 123.9, 120.1, 117.5, 115.6, 114.9, 71.3, 70.7. HRMS-ESI $(\mathrm{m} / \mathrm{z}):\left[\mathrm{M}+\mathrm{NH}_{4}\right]^{+}$calcd. for $\mathrm{C}_{31} \mathrm{H}_{24} \mathrm{~N}_{5} \mathrm{O}_{3}$, 514.18737; found, 514.18728. Anal. calcd. for $\mathrm{C}_{31} \mathrm{H}_{20} \mathrm{~N}_{4} \mathrm{O}_{3}$ : C, 74.99; H, 4.06; N, 11.28. Found: C, 74.49; $\mathrm{H}, 4.08 ; \mathrm{N}, 10.95$.

\section{Results and discussion}

\subsection{Synthesis of dendritic poly(benzyl ether) gelators}

The synthetic route and molecular structures of IPN-functionalized poly(benzyl ether) dendrons $\mathrm{G}_{m}-\mathrm{CN}(m=1,2)$ were outlined in Scheme 1. According to our previous methods $[24,30]$, a series of peripherally isophthalonitrile-functionalized poly(benzyl ether) dendrons were divergently synthesized by using Mitsunobu reaction between the first- and second-generation dendritic alcohols with commercially available 5-hydroxyisophthalonitrile in $70 \%$ and $85 \%$ yields, respectively. Their chemical structures and purities were confirmed by ${ }^{1} \mathrm{H}$ NMR, ${ }^{13} \mathrm{C}$ NMR and HR-ESI mass spectroscopy as well as elemental analysis.

\subsection{Organogelation behavior}

The gelation abilities of these dendrons $\mathrm{G}_{m}-\mathrm{CN}(m=1,2)$ in various organic solvents were investigated by the "stable to inversion in a test tube" method. As shown in Table 1 , it was found that the second-generation dendron $\mathrm{G}_{2}-\mathrm{CN}$ displayed stronger gelation ability than $\mathrm{G}_{1}-\mathrm{CN}$. $\mathrm{G}_{2}-\mathrm{CN}$ could form stable gels in various organic solvents including 10 organic solvents and 2 mixed solvents tested herein. For example, the critical gelation concentrations (CGCs) of $\mathrm{G}_{2}-\mathrm{CN}$ in acetonitrile and 3-pentanone were as low as 3.8 and $6.3 \mathrm{mg} / \mathrm{mL}$, indicating that one dendritic molecule could entrap about $5.17 \times 10^{3}$ and $1.15 \times 10^{3}$ solvent molecules, respectively. In addition, the organogels of $\mathrm{G}_{2}-\mathrm{CN}$ were very stable for months and exhibit thermally reversible sol-gel transitions. In contrast, the first-generation dendron $\mathrm{G}_{1}-\mathrm{CN}$ could not self-assemble into stable gels in organic liquids, indicating that the dendron generation exhibited an intriguing effect on the gelation efficiency.

\subsection{Gel-sol phase transition temperature}

The gel-sol phase transition temperatures $\left(T_{\text {gel }}\right)$ of the $\mathrm{G}_{2}-\mathrm{CN}$ gels in acetonitrile as a function of a concentration were determined by the tube-inversion method (Figure 1). In general, $T_{\text {gel }}$ increased as the concentration increased, which indicated that the stability of the gel was enhanced with the increase of the concentration.

\subsection{Morphologies of the xerogels}

To obtain visual images of the aggregation structures from various organic solvents, the morphology of the dendritic xerogels of $\mathrm{G}_{2}-\mathrm{CN}$ was investigated by scanning electron microscopy (SEM). As shown in Figure 2, fiberlike or ribbonlike morphologies in different organic solvents were observed. For example, the xerogels of $\mathrm{G}_{2}-\mathrm{CN}$ from 3-pentanone, ethyl acetate, acetonitrile, cyanobenzene and

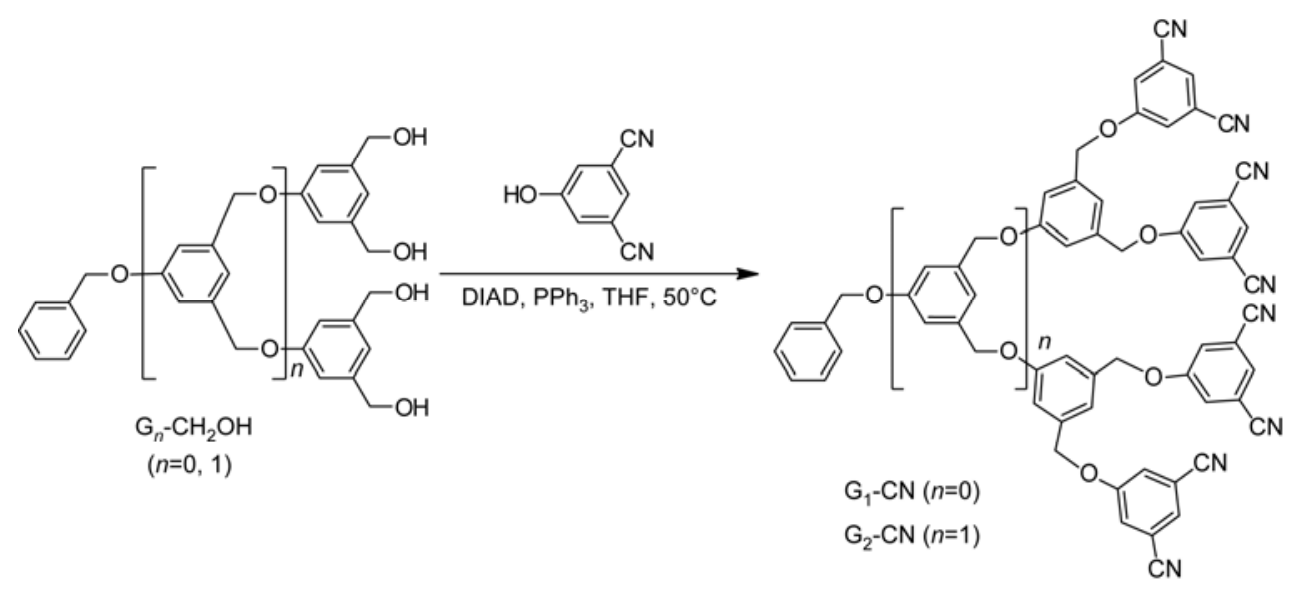

Scheme 1 Synthetic route and chemical structures of dendritic poly(benzyl ether) gelators $\mathrm{G}_{1}-\mathrm{CN}_{\text {and }} \mathrm{G}_{2}-\mathrm{CN}$. 
Table 1 Gelation properties and values of CGCs in organic solvents ${ }^{\text {a) }}$

\begin{tabular}{|c|c|c|}
\hline Solvents & $\mathrm{G}_{1}-\mathrm{CN}$ & $\mathrm{G}_{2}-\mathrm{CN}$ \\
\hline Toluene & PG & I \\
\hline Pyridine & PG & $\mathrm{G}(34.0)$ \\
\hline Cyanobenzene & PG & $\mathrm{G}(13.1)$ \\
\hline Benzylalcohol & PG & $\mathrm{G}(23.6)$ \\
\hline Ethyl acetate & I & $\mathrm{G}(18.2)$ \\
\hline Acetone & $\mathrm{P}$ & $\mathrm{G}(22.8)$ \\
\hline Acetonitrile & $\mathrm{P}$ & $\mathrm{G}(3.8)$ \\
\hline 2-Methoxyethanol & I & $\mathrm{G}(25.7)$ \\
\hline Tetrachloromethane & I & I \\
\hline 1, 2-Dichloroethane & $\mathrm{P}$ & $\mathrm{G}(14.8)$ \\
\hline Nitromethane & $P$ & $\mathrm{G}(11.5)$ \\
\hline 3-Pentanone & $\mathrm{P}$ & $\mathrm{G}(6.3)$ \\
\hline $\mathrm{CHCl}_{3} / \mathrm{CH}_{3} \mathrm{CN}=1: 9$ & $\mathrm{P}$ & $\mathrm{G}(5.3)$ \\
\hline $\mathrm{THF} / \mathrm{CH}_{3} \mathrm{OH}=3: 1$ & I & G (19.6) \\
\hline Pyridine $/ \mathrm{H}_{2} \mathrm{O}=4: 1$ & PG & PG \\
\hline Anisole $/ \mathrm{CCl}_{4}=3: 2$ & I & PG \\
\hline
\end{tabular}

a) Critical gelation concentrations (CGCs) at room temperature $\left(20^{\circ} \mathrm{C}\right)$ are given in $\mathrm{mg} / \mathrm{mL}$. G, gel; PG, partial gel; I, insoluble; S, soluble; P, precipitation.

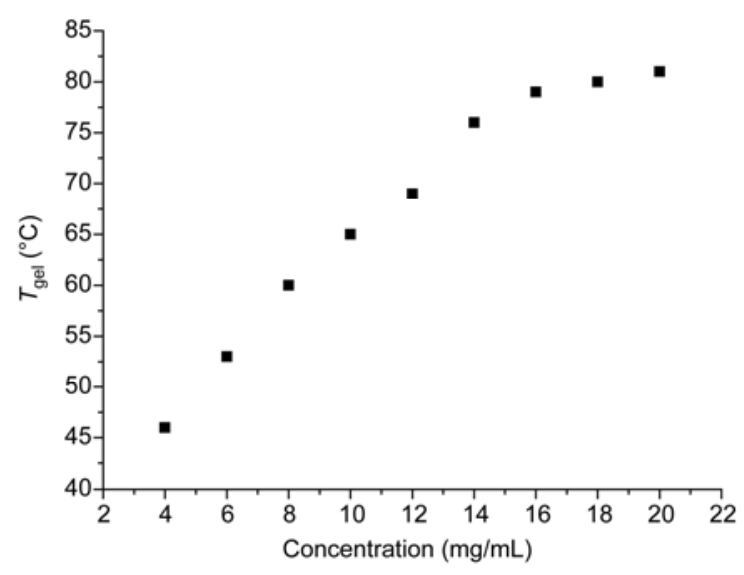

Figure 1 The determined gel-solution transition temperatures $\left(T_{\text {gel }}\right)$ for $\mathrm{G}_{2}-\mathrm{CN}$ in acetonitrile at various concentrations. The data were the averaged value of two runs. The relative errors for all of the $T_{\text {gel }}$ 's are within $1^{\circ} \mathrm{C}$.

2-methoxyethanol exhibited three-dimensional fibrillar networks, which were formed by numerous intertwined fibers with high aspect ratios, widths of $20-80 \mathrm{~nm}$, and lengths of several micrometers. However, the xerogels from 1,2-dichloroethane and acetone exhibited shorter and larger fibrillar structures with diameters of $\sim 100-300 \mathrm{~nm}$. Notably, in nitromethane, the xerogel showed a smooth ribbon structure with the width of the ribbon in the range of $0.5-2.0 \mu \mathrm{m}$. On the basis of the above SEM results, we can see that the morphology of the xerogels depends on the nature of the gelling solvents.
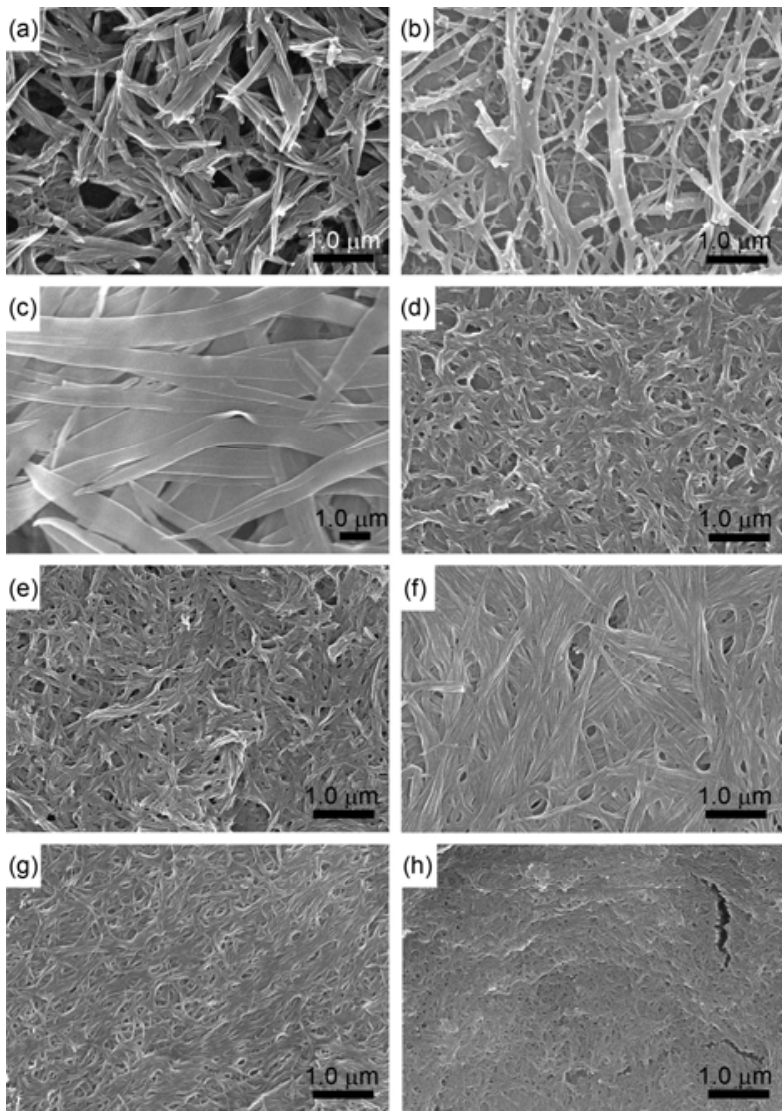

Figure 2 SEM images of the corresponding xerogels of $\mathrm{G}_{2}-\mathrm{CN}$ from: (a) 1,2-dichloroethane, (b) acetone, (c) nitromethane, (d) 3-pentanone, (e) ethyl acetate, (f) acetonitrile, (g) cyanobenzene, (h) 2-methoxyethanol.

\subsection{The driving force for gelation}

In order to investigate the driving forces leading to the formation of the organogels, single-crystal X-ray diffraction of $\mathrm{G}_{1}-\mathrm{CN}$ was firstly performed. The crystal structure and packing diagram of $\mathrm{G}_{1}-\mathrm{CN}$ were shown in Figure 3. It was noted that the peripheral isophthalonitrile rings (electrondeficient "head") adopt a planar geometry, and all of them were coplanar with the internal benzyl ring (electron-rich "tail"). The two neighboring extended planes were stacked in head-to-tail pairs with inter-planar distances of ca. $3.41 \AA$ (Figure 3(c)), indicative of strong $\pi-\pi$ interactions. Also, another of the peripheral isophthalonitrile rings adopts the "J-aggregation" $\pi-\pi$ interaction mode with the peripheral isophthalonitrile rings of other molecules. Intermolecular $\mathrm{C}-\mathrm{H} \cdots \mathrm{N} \equiv \mathrm{C}$ hydrogen-bonding interactions $(2.45-2.62 \AA)$ were also found in the crystal structure (Figure 3(c) and (d)), which was shorter than the van der Waals distance of about $2.7 \AA$. To the best of our knowledge, this is the first example of intermolecular assembly of IPN-based systems that form supramolecular dendritic aggregations.

The molecular aggregation behavior of compound $\mathrm{G}_{1^{-}}$ $\mathrm{CN}$ in solution was further confirmed by concentrationdependent (CD) and temperature-dependent (TD) ${ }^{1} \mathrm{H}$ NMR 
(a)

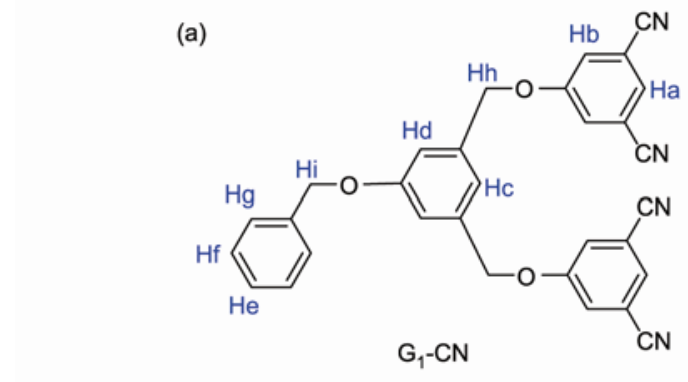

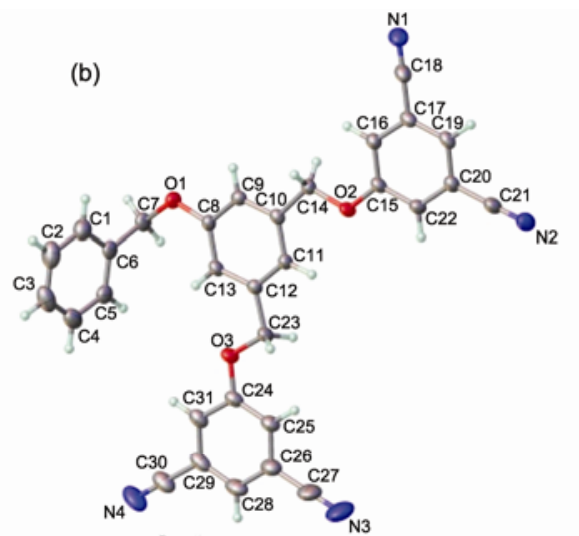

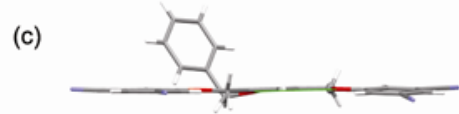

(c)

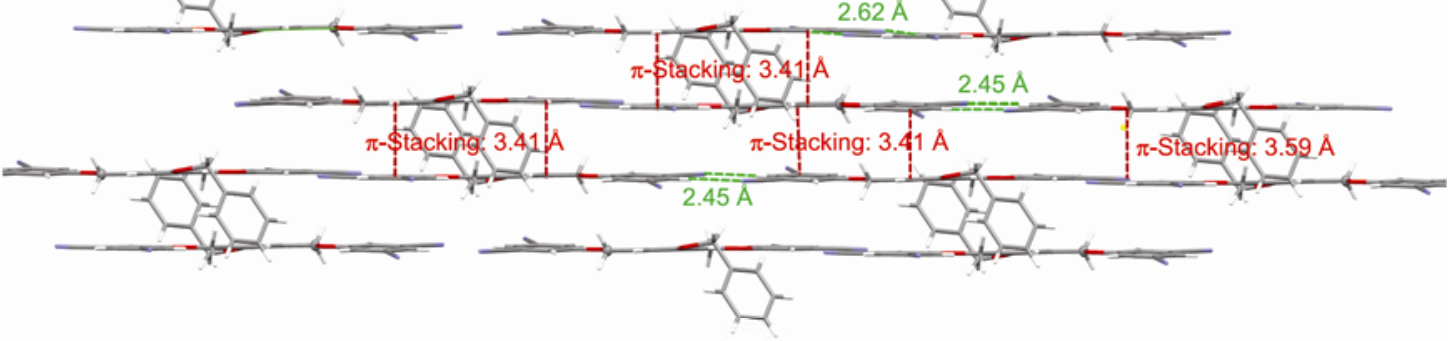

(1)

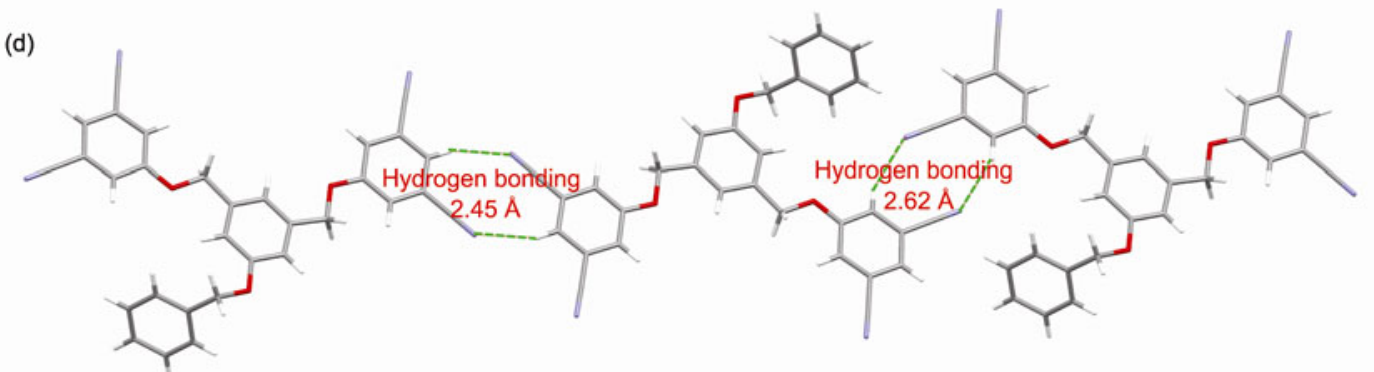

Figure 3 (a) and (b) Molecular structure of $\mathrm{G}_{1}-\mathrm{CN}$ in the crystal; (c) $\pi-\pi$ stacking and $\mathrm{C}-\mathrm{H} \cdots \mathrm{N} \equiv \mathrm{C}$ hydrogen bonding; (d) $\mathrm{C}-\mathrm{H} \cdots \mathrm{N} \equiv \mathrm{C}$ hydrogen bonding in the crystal of $\mathrm{G}_{1}-\mathrm{CN}$.

spectroscopy studies. In the $\mathrm{CD}-{ }^{1} \mathrm{H}$ NMR experiments, as the concentration was increased from 0.05 to $44 \mathrm{mmol} / \mathrm{L}$, the chemical shifts of the aromatic protons on the peripheral IPN rings ( $\mathrm{Ha}$ and $\mathrm{Hb}$ ) and the internal benzyl rings ( $\mathrm{Hc}$ and Hd) showed upfield shift by a range of 0.005-0.013. (Figure 4(a)). In addition, the chemical shifts of all the aliphatic protons ( $\mathrm{Hh}$ and $\mathrm{Hi}$ ) nearby the aromatic also found upfield shift in experiments. It should be noted that peak broadening was observed as the concentration increased because of restricted molecular motion. Regarding the TD- ${ }^{1} \mathrm{H}$ NMR experiments, these resonance signals were found to be gradually shifted downfield when the temperature increased from 10 to $50^{\circ} \mathrm{C}$ (Figure 4(b)). This chemical shift change of the aromatic protons with concentration was consistent with that of the temperature dependence, which implied $\pi-\pi$ stacking between $\mathrm{G}_{1}-\mathrm{CN}$ molecules [31,32].

Based on all the above experimental evidences and our previous study on peripherally dimethyl isophthalate-functionalized dendritic analogues [24], the extended aromatic plane consisting of the IPN ring and the benzyl ring at the periphery of the dendritic gelators could be served as a new type of gelation "motif" to improve multi-intermolecular interactions. Thus, the principal multiple strong $\pi-\pi$ aromatic stacking interactions, together with hydrogen bonding and solvophobic interactions, might best explain the origin of this unique gelation capability of these poly(benzyl ether) dendrons without bearing any conventional gelation motifs.

\section{Conclusions}

In summary, peripherally isophthalonitrile-functionalized poly(benzyl ether) dendrons of the first- and second-generation have been successfully synthesized and their gelation properties were investigated. It was found that their gelation property was highly dependent on the dendritic generation. As an efficient dendritic gelator, $\mathrm{G}_{2}-\mathrm{CN}$ could form stable gels in various aromatic and polar organic solvents. X-ray single crystal structure analysis and concentration- and temperature-dependent ${ }^{1} \mathrm{H}$ NMR spectra of $\mathrm{G}_{1}-\mathrm{CN}$ revealed 
(a)
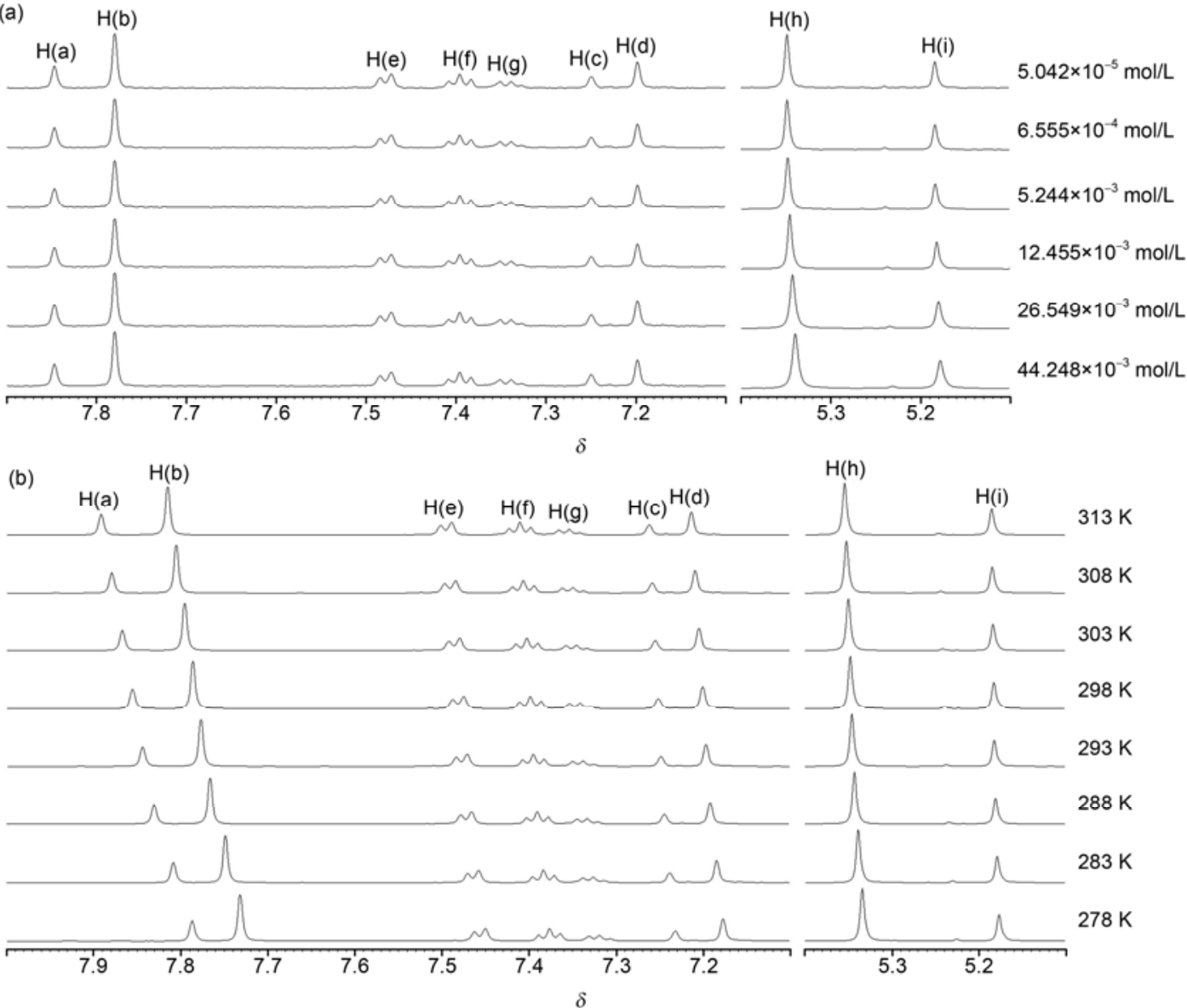

Figure 4 Partial ${ }^{1} \mathrm{H}$ NMR spectra $\left(600 \mathrm{MHz}, \mathrm{CH}_{3} \mathrm{CN}\right)$ of $\mathrm{G}_{1}-\mathrm{CN}$ at (a) different concentrations at $25^{\circ} \mathrm{C}$ and (b) variable temperature at the concentration of $12.455 \mathrm{mmol} / \mathrm{L}$ (using TMS as internal standard).

that multiple strong $\pi-\pi$ stacking interactions and hydrogen bonding due to the peripheral isophthalonitrile motifs were the key contributor in forming the self-assembled gel. As a new type of gelation "motif", further study on their applications in functional nanomaterials is in progress.

We thank Prof. Junfeng Xiang in the Institute of Chemistry, Chinese Academy of Sciences and Prof. Dongsheng Liu in Tsinghua University for helpful discussions. This work was supported by the National Natural Science Foundation of China (21074140 and 91027046) and Institute of Chemistry, Chinese Academy of Sciences.

1 Hirst A R, Smith D K. Dendritic gelators. Top Curr Chem, 2005, 256: 237-373

2 SmithD K. Dendritic gels: Many arms make light work. Adv Mater, 2006, 18: 2773-2778

3 Grinstaff M W. Dendritic macromers for hydrogel formation: Tailored materials for ophthalmic, orthopedic, and biotech applications. J Poly Sci A-Poly Chem, 2008, 46: 383-400

4 Newkome G R, Baker G R, Saunders M J, et al. Two-directional cascade molecules: Synthesis and characterization of [9]-n-[9] a rborols. Chem Soc Chem Commun, 1986: 752-753

5 Newkome G R, Baker G R, Arai S, et al. Synthesis and characterization of two-directional cascade molecules and formation of aqueous gels. J Am Chem Soc, 1990, 112: 8458-8465

6 Marmillon C, Gauffre F, Majoral J P, et al. Organophosphorus den- drimers as new gelators for hydrogels. Angew Chem Int Ed, 2001, 40: 2626-2629

7 Jang W D, Jiang D L, Aida T. Dendritic physical gel: Hierarchical self-organization of a peptide-core dendrimer to form a micrometerscale fibrous assembly. J Am Chem Soc, 2000, 122: 3232-3233

8 Zubarev E R, Pralle M U, Stupp S I, et al. Self-assembly of dendron rod-coil molecules into nanoribbons. J Am Chem Soc, 2001, 123: 4105-4106

9 Kim C, Kim K T, Chang Y, et al. Supramolecular assembly of amide dendrons. J Am Chem Soc, 2001, 123: 5586-5587

10 Partridge K S, Smith D K, Dykes G M, et al. Supramolecular dendritic two-component gel. Chem Commun, 2001, 319-320

11 Huang B Q, Hirst A R, Smith D K, et al. A direct comparison of oneand two-component dendritic self-assembled materials: Elucidating molecular recognition pathways. J Am Chem Soc, 2005, 127: 71307139

12 Ji Y, Luo Y F, Jia X R, et al. A dendron based on natural amino acids: Synthesis and behavior as an organogelator and lyotropic liquid crystal. Angew Chem Int Ed, 2005, 44: 6025-6029

13 Kuang G C, Ji Y, Jia X R, et al. Self-assembly of amino-acid-based dendrons: Organogels and lyotropic and thermotropic liquid crystals. Chem Mater, 2008, 20: 4173-4175

14 Kuang G C, Jia X R, Chen E Q, et al. Organogels and liquid crystalline properties of amino acid-based dendrons: A systematic study on structure-property relationship. Chem Mater, 2012, 24: 71-80

15 Chow H F, Zhang J. Structural diversity of a-amino acid based layerblock dendrons and their layer-block sequence-dependent gelation properties. Chem Eur J, 2005, 11: 5817-5831

16 Lau K N, Chow H F, Chan M C, et al. Dendronized polymer organo- 
gels from click chemistry: A remarkable gelation property owing to synergistic functional-group binding and dendritic size effects. Angew Chem Int Ed, 2008, 47: 6912-6916

17 Percec V, Peterca M, Yurchenko M E, et al. Thixotropic twin-dendritic organogelators. Chem Eur J, 2008, 14: 909-918

18 Yang M, Wang W, Wegner G, et al. Self-assembled structures in organogels of amphiphilic diblock codendrimers. Chem Eur J, 2008, 14: 3330-3337

19 Duan P F, Liu M H. Design and self-assembly of $L$-glutamate-based aromatic dendrons as ambidextrous gelators of water and organic solvents. Langmuir 2009, 25: 8706-8713

20 Chen Y L, Bo Z S, Liu C Y, et al. Dendritic effect on supramolecular self-assembly: Organogels with strong fluorescence emission induced by aggregation. Langmuir, 2009, 25: 8548-8555

21 Seo M, Kim J H, Kim S Y, et al. Self-association of bis-dendritic organogelators: The effect of dendritic architecture on multivalent cooperative interactions. Chem Eur J, 2010, 16: 2427-2441

22 Yang X C, Lu R, Gai F Y. Rigid dendritic gelators based on oligocarbazoles. Chem Commun, 2010, 46: 1088-1090

23 Rajamalli P, Prasad E. Luminescent micro and nanogel formation from $\mathrm{AB}_{3}$ type poly(aryl ether) dendron derivatives without conventional multi-interactive gelation motifs. New J Chem, 2011, 35: 1541-1548

24 Feng Y, He Y M, Fan Q H, et al. Peripherally dimethyl isophthalatefunctionalized poly(benzyl ether) dendrons: A new kind of unprecedented highly efficient organogelators. J Am Chem Soc, 2009, 131: 7950-7951
25 Chen Q, Zhang D Q, Fan Q H, et al. Light-triggered self-assembly of a spiropyran-functionalized dendron into nano-/micrometer-sized particles and photoresponsive organogel with switchable fluorescence. Adv Funct Mater, 2010, 20: 36-42

26 Barclay T M, Cordes A W, Oakley R T, et al. Oligothiophenes endcapped by nitriles. Preparation and crystal structures of $\alpha, \omega$-dicyanooligothiophenes $\mathrm{NC}_{2}\left(\mathrm{C}_{4} \mathrm{H}_{2} \mathrm{~S}\right)_{n} \mathrm{CN}$ (n=3-6). Chem Mater, 1997, 9: 981-990

27 Nishida J, Shio Murai N, Yamashita Y, et al. Preparation, characterization, and FET properties of novel dicyanopyrazinoquinoxaline derivatives. Org Lett, 2004, 6: 2007-2010

28 Jang K, Kinyanjui J M, Lee D C, et al. Morphological control of one-dimensional nanostructures of t-shaped asymmetric bisphenazine. Chem Mater, 2009, 21: 2070-2076

29 Eldridge J E, Ferry J D. Studies of the cross-linking process in gelatin gels. III. Dependence of melting point on concentration and molecular weight. J Phys Chem, 1954, 58: 992-995

30 Feng Y, He Y M, Fan Q H, et al. A liquid-phase approach to functionalized janus dendrimers: Novel soluble supports for organic synthesis. Org Lett, 2007, 9: 2261-2264

31 Fernández G, Sánchez L, Martín N, et al. Large exTTF-based dendrimers. Self-assembly and peripheral cooperative multiencapsulation of $\mathrm{C}_{60}$. J Am Chem Soc, 2008, 130: 10674-10683

32 Yang H, Yi T, Li F Y, et al. Switchable fluorescent organogels and mesomorphic superstructure based on naphthalene derivatives. Langmuir, 2007, 23: 8224-8230

Open Access This article is distributed under the terms of the Creative Commons Attribution License which permits any use, distribution, and reproduction in any medium, provided the original author(s) and source are credited. 